\title{
COMMENT
}

\section{The challenges of planetary mental health in the COVID-19 era}

\author{
KONSTANTINOS TSAMAKIS ${ }^{1,2}$, GEORGIOS DIMITRAKAKIS ${ }^{3}$, ELLIE STEFANADI ${ }^{4}$, \\ DIMITRIOS TSIPTSIOS ${ }^{5}$, INETZI A. DIMITRAKAKI ${ }^{6}$, CHRISTOPH MUELLER $^{2}$, \\ DEMETRIOS A. SPANDIDOS ${ }^{7}$, CHRISTODOULOS STEFANADIS ${ }^{8}$ and EMMANOUIL RIZOS ${ }^{1}$
}

\begin{abstract}
${ }^{1}$ Second Department of Psychiatry, University of Athens, 'ATTIKON' University Hospital, 12462 Athens, Greece;
${ }^{2}$ King's College London, Institute of Psychiatry, Psychology and Neuroscience, London SE5 8AF; ${ }^{3}$ Department of Cardiothoracic Surgery, University Hospital of Wales, Cardiff CF14 4XW, UK; ${ }^{4}$ Medical Center of Athens, 15125 Athens, Greece; ${ }^{5}$ Neurophysiology Department, South Tyneside and Sunderland NHS Foundation Trust, Sunderland SR47TP, UK; ${ }^{6}$ Metropolitan Hospital of Athens, 18547 Athens; ${ }^{7}$ Laboratory of Clinical Virology, School of Medicine, University of Crete, 71003 Heraklion; ${ }^{8}$ Medical School of Athens, National and Kapodistrian University of Athens, 11527 Athens, Greece
\end{abstract}

Received June 12, 2020; Accepted June 24, 2020

DOI: $10.3892 /$ etm.2020.8927

\begin{abstract}
As the focus of the COVID-19 crisis is gradually taken away from emergency healthcare needs, increased attention is warranted on the psychological impact of the pandemic on a global level. Existing guidance on managing the COVID-19 related distress needs to be better informed by upcoming larger-scale research. Applying e-Health can be useful in dealing with the immediate psychological needs, while developing strategies to identify vulnerable populations and shifting the provision of mental health and social care to community services need to be prioritised when looking at the future. Focusing on global mental health during this universal crisis is an opportunity for promoting a more compassionate and less discriminating society.
\end{abstract}

While COVID-19 continues its lethal spread (1) and the focus on dealing with the immediate healthcare needs is reducing, it is increasingly important to acknowledge the significant psychological burden on global mental health. The stress surrounding COVID-19 ('COVID-stress') has not only been affecting the mental well-being of individuals and local communities (2); it has created an almost global psychological distress (3). Although it is nearly half a year into the pandemic, we are still steering through unchartered waters, whilst the endpoint of COVID-19 is still not in sight. The anxiety stemming from the inability to neither 'fight or fly' away from the virus and the mourning of the loss of our everyday routine

Correspondence to: Dr Konstantinos Tsamakis, Second Department of Psychiatry, University of Athens, 'ATTIKON' University Hospital, Rimini 1, Chaidari, 12462 Athens, Greece

E-mail: ktsamakis@gmail.com

Key words: COVID-19, pandemic, challenges, global, mental health, planetary, stress, social transformation and feeling of safety continue to be prevalent. As the crisis becomes more prolonged, this comes along with an estimated increase in mental health problems (3). As a result, it becomes increasingly important to focus our attention on the largest public mental health crisis of our generation, drawing on lessons being learnt, applying fast-tracked, efficient and innovative interventions and building on opportunities arising from this unparalleled challenge.

Guidance by the World Health Organisation (WHO) and governments around the world on dealing with psychological distress in the COVID-19 era seem not to be enough. Although emerging literature already highlights the detrimental psychological impact of COVID-stress in the general population and vulnerable groups (healthcare workers, elderly, children, people with pre-existing physical and mental health problems) (4-7) the unprecedent magnitude of this pandemic means we need substantially additional and well-planned research to better understand the short- and long-term severity of COVID-19 related mental health problems and how to deal with them. The better evidence-based knowledge will allow the public health authorities better planning and transition of care plus proper allocation of relevant resources. Fortunately, numerous studies are underway in many different countries, including large international efforts investigating the impact of COVID-19 on mental health during and after the pandemic (8).

Focusing on the immediate psychological impact of the crisis through timely and efficient interventions, including convenient and inexpensive e-Health strategies, such as interactive telemedicine along with synchronous and asynchronous social media and virtual care tools (9) is of utmost importance. Dealing with the individual and collective trauma associated with the pandemic is essential; however, it should be done by integrating in our approach the specific culturally relevant care needs, existing socioeconomic inequalities, and complexities of co-existing mental health problems (10). Increasing aware- 
ness and acknowledging common behavioural patterns in times of uncertainty, including fear of the unknown and ingrained societal norms, is essential to facilitate positive behavioural change and address potential 'pitfalls of judgement' (11).

In the longer term, identifying the most vulnerable groups at risk of mental health deterioration is a priority; in light of this there have been calls to shift focus to population based screening (using psychiatric screening questionnaires in primary care and technological-savvy approaches) rather than an individual based approach (3). Although this is welcome, it needs to be carefully balanced with the need to keep the individual patient in the centre of care (12), whilst looking after those, i.e., the healthcare staff, who care for them (13).

The need for reorganisation of mental health services on a global scale, in order to be able to accommodate the increased needs of the population is becoming more apparent. WHO has called for increased financial investment in global mental health to build a 'fit for the future' mental health system, suggesting an increasing shift of mental health and social care towards community services, and inclusion of mental health conditions in health insurance coverage (14). The scientific community and more specifically the medical societies can play a pivotal and protagonistic role in this quest. We need healthcare systems that offer sustainable, holistic, evidence-based, tailored to the individual and beyond the short term mental health care.

The complex social, psychological and humanitarian challenges of this ongoing pandemic require a mental health focus on a global level. The universal nature of this biothreat, against which we are all emotionally vulnerable, regardless of gender, skin colour, religion or ethnicity is an opportunity for global mental health not only to be reshaped, but also to placed in the epicentre of a larger social transformation (15), aiming for a world with less prejudice, discrimination and stigma. Amidst this novel, unequalled crisis, focusing on planetary mental health means promoting a more compassionate society (16).

\section{Acknowledgements}

Not applicable.

\section{Funding}

No funding was received.

\section{Availability of data and materials}

Not applicable

\section{Authors' contributions}

KT wrote the original draft, edited and critically revised the manuscript. GD contributed substantially in the writing of the manuscript, critically revised and edited the manuscript. ES, ER, DT, CS, IAD, DAS and CM critically revised and edited the manuscript. All authors substantially contributed to the conception, writing and revision of the work and approved the final content of the manuscript.

\section{Ethics approval and consent to participate}

Not applicable.

\section{Patient consent for publication}

Not applicable.

\section{Competing interests}

DAS is the Editor-in-Chief for the journal, but had no personal involvement in the reviewing process, or any influence in terms of adjudicating on the final decision, for this article. The other authors declare that they have no competing interests.

\section{References}

1. Docea AO, Tsatsakis A, Albulescu D, Cristea O, Zlatian O, Vinceti M, Moschos SA, Tsoukalas D, Goumenou M, Drakoulis N, et al: A new threat from an old enemy: Re-emergence of coronavirus (Review). Int J Mol Med 45: 1631-1643, 2020.

2. Pfefferbaum B and North CS: Mental health and the Covid-19 pandemic. N Engl J Med: April 13, 2020 (Epub ahead of print).

3. No authors listed: Keep mental health in mind. Nat Med 26: 631, 2020.

4. Tsamakis K, RizosE, Manolis A J, Chaidou S, Kympouropoulos S, Spartalis E, Spandidos DA, Tsiptsios D and Triantafyllis AS: [Comment] COVID-19 pandemic and its impact on mental health of healthcare professionals. Exp Ther Med 19: 3451-3453, 2020.

5. Tsamakis K, Triantafyllis AS, Tsiptsios D, Spartalis E, Mueller C, Tsamakis C, Chaidou S, Spandidos DA, Fotis L, Economou M and Rizos E: COVID 19 related stress exacerbates common physical and mental pathologies and affects treatment (Review). Exp Ther Med 20: 159-162, 2020.

6. Pappa S, Ntella V, Giannakas T, Giannakoulis VG, Papoutsi E and Katsaounou P: Prevalence of depression, anxiety, and insomnia among healthcare workers during the COVID-19 pandemic: A systematic review and meta-analysis. Brain Behav Immun: May 8, 2020 (Epub ahead of print).

7. Tsamakis K, Gavriatopoulou M, Schizas D, Stravodimou A, Mougkou A, Tsiptsios D, Sioulas V, Spartalis E, Sioulas AD, Tsamakis C, et al: Oncology during the COVID-19 pandemic: challenges, dilemmas and the psychosocial impact on cancer patients (Review). Oncol Lett 20: 441-447, 2020.

8. The Collaborative Outcomes Study on Health and Functioning during Infection Times (COH-FIT). COH-FIT, 2020. https://www.coh-fit.com/. Accessed May 17, 2020.

9. Hollander JE and Carr BG: Virtually perfect? Telemedicine for Covid-19. N Engl J Med 382: 1679-1681, 2020.

10. The Lancet Psychiatry: Send in the therapists? Lancet Psychiatry 7: 291, 2020.

11. Redelmeier DA and Shafir E: Pitfalls of judgment during the COVID-19 pandemic. Lancet Public Heal 5: e306-e308, 2020.

12. World Health Organisation (WHO): Statement - Invest in the overlooked and unsung: build sustainable people-centred long-term care in the wake of COVID-19. WHO, Geneva, 2020.

13. Dzau VJ, Kirch D and Nasca T: Preventing a Parallel Pandemic - A National Strategy to Protect Clinicians' Well-Being. N Engl J Med: May 13, 2020 (Epub ahead of print).

14. World Health Organisation (WHO): Substantial investment needed to avert mental health crisis. WHO, Geneva, 2020.

15. Ahmad A, Mueller C and Tsamakis K: Covid-19 pandemic: A public and global mental health opportunity for social transformation? BMJ 369: m1383, 2020.

16. Jakovljevic M, Bjedov S, Jaksic N and Jakovljevic I: COVID-19 pandemia and public and global mental health from the perspective of global health security. Psychiatr Danub 32: 6-14, 2020.

This work is licensed under a Creative Commons Attribution-NonCommercial-NoDerivatives 4.0 International (CC BY-NC-ND 4.0) License. 